\title{
Gender Inclusiveness in Prevention of Mother to Child Transmission Programme in KwaZulu-Natal: Male Perspectives
}

\author{
R. M. Miya ${ }^{1}$, T. Mgutshini' \\ ${ }^{1}$ Durban University of Technology, Faculty of Health Sciences, Department of Nursing Science, Durban, South Africa \\ ${ }^{2}$ University of South Africa, Faculty of Humanities, Tuition Department, Pretoria, South Africa
}

Email address:

mondymia@yahoo.com (R. M. Miya),mgutst@unisa.ac.za (T. Mgutshini)

\section{To cite this article:}

R. M. Miya, T. Mgutshini. Gender Inclusiveness in Prevention of Mother to Child Transmission Programme in KwaZulu-Natal: Male Perspectives. American Journal of Nursing Science. Vol. 4, No. 5, 2015, pp. 280-287. doi: 10.11648/j.ajns.20150405.15

\begin{abstract}
Background: Most developing and developed countries require PMTCT to preserve humanity and children's survival. All dynamics around PMTCT implementation seek commitment from all stakeholders at different levels to ensure elimination of new HIV infections in children. In 2010, $48 \%$ of pregnant women living with HIV in low and middle income countries (716 500 of 1.49 million) received effective antiretroviral regimens excluding single dose nevarapine. An estimated $35 \%$ of pregnant women living with HIV in low and middle countries received an HIV test in 2010, up from 7\% in 2005. HAART coverage has increased from 1.48 million infants born to mothers living with HIV to $32 \%$ to $42 \%$. Objectives: The purpose of the study was to explore and describe the range of barriers and motivational factors for gender inclusiveness within the (Prevention of mother to child transmission) PMTCT programme in public hospitals in KwaZulu-Natal as perceived by males. Methodology: A qualitative, descriptive, explorative study was conducted through individual interview of males until data saturation. Results: The findings of the study reveal that; males were not aware of their role in the prevention of mother to child transmission and did not feel comfortable to be in the mist of pregnant women. Conclusion: The study recommends intense male recruitment into PMTCT to ensure effective management of HIV in pregnancy and to prevent MTCT. This will ensure a holistic support needed by pregnant women on PMTCT.
\end{abstract}

Keywords: PMTCT, HIV

\section{Introduction}

The Republic of South Africa (RSA) like all other developing countries is affected by the HIV/AIDS epidemic, with about 3, 5 million people known to be living with the virus or disease (World Health Organisation, 2010). HIV/AIDS is the leading cause of death in RSA (World Health Organisation and International Monetary Fund, 2013).

Approximately one million children will have lost their parents to the disease by 2015. (World Health Organisation, 2010a) The epidemic disproportionately affects the young black and economically poor populations in RSA (WHO, 2010). Within South Africa, mother to child transmission represents a significant area of concern for two specific reasons. Firstly, the national rate of $2.8 \%$ of mother to baby transmission is appreciably above the target rate of zero percent transmission by 2015 set by the World Health Organisation. The uptake and continued adherence with
Prevention of Mother to Child Transmission (PMTCT) health services is lower than expected and most notably, KwaZulu Natal province reports the highest provincial rate of mother to baby transmission of $3.7 \%$ in the country. (KZN Health, 2012; UNFPA, 2011).

As of 2011, the Centre for Disease Control (CDC, 2011) confirmed that over 34 million people globally were living with HIV/AIDS. 22.9 million (nearly $68 \%$ ) of this represents infections within sub-Saharan Africa (CDC, 2011). In real terms, this translates to the fact that 3 out of every 4 people infected with HIV /AIDS live in sub-Saharan Africa. Affected by the HIV/AIDS epidemic, the Republic of South Africa (RSA), much like other developing countries has about 3, 5 million people known to be living with the virus or disease (WHO, 2012). HIV/AIDS has had a noteworthy negative effect on life expectancy within Africa and most 
specifically within RSA. On the continent of Africa the average life expectancy has reduced from 59.4 years to 51.2 years, primarily because of the impact of HIV and AIDS. (WHO, 2012). HIV /AIDS has proved particularly problematic because of a number of widely published unique characteristics including the fact that (i) significant behavioural changes in the sexual practices of populations is required in order to manage of the spread of HIV/AIDS, (ii) the identity of a cure to the virus remains elusive, (iii) HIV/AIDS has a wide symptom spectrum that is difficult to effectively manage and finally, (iv) the prognosis of affected individuals is correlated with socioeconomic status i.e. individuals from poorer backgrounds have much less favourable survival outcomes compared to their materially advantaged counterparts (WHO, 2012). This combination of factors places Africa at an increased risk of higher-thanaverage mortality rates when compared to other global continents. This trajectory is borne out by statistics from the World Health Organisation (WHO) which confirms the pandemic prevalence of HIV/AIDS.

With such a high rate of incidence, it is clear that HIV/AIDS represents the most significant clinical challenge facing health providers, clinicians and the world's population. The high incidence of HIV/AIDS is reported in 33 countries globally and 22 countries out of the 33 are in the SubSaharan region and the rest are distributed in Eastern Europe and Central Asia (UNAIDS, 2011). Nationally, as of 2011, the estimated overall HIV prevalence was an estimated 5.38 million people (10.6\% of the national population). Among those aged $15-49$ years, an estimated $16.6 \%$ of the population are HIV positive 316000 new year on year infections are reported, with $63000(20 \%)$ of these new cases being reported in children between the ages of zero and 14 years old (Statistics South Africa, 2011).

The Sub-Saharan region is not the only the focal nexus of the HIV/AIDS burden, it is the region where populations have the highest risk of continued infection (WHO, 2010). Of the 2.7 million newly infected adults and babies reported in 2010, 1.9 million (over 70\%) were in Sub-Saharan Africa (WHO, 2011). This is at least 8 times the rate of infection reported in South and South-East Asia, the region with the second highest rates of new cases at 270 000. (WHO, 2011). Given the continued excessively high rates of infection, interventions to prevent transmission of HIV/AIDS have retained centre stage importance as the most promising means by which the impact of HIV/AIDS will be reduced with time.

The global HIV/AIDS reduction programme has identified six specific interventions requiring prioritisation and these include: (i) increasing the percentage of people who receive a HIV test in the past 12 months and know their status. (ii) Increasing the proportion of people receiving anti-retroviral therapy (ART). (iii) rates of reported condom use at last sexual encounter. (iv) Reduction of incidence, prevalence and death rates associated with tuberculosis and most relevant to the current study. (vi) The reduction in mother to child transmission of HIV (WHO, 2012).

\section{Background}

A study conducted in Botswana on the role of a male in PMTCT reveals promising results that can improve PMTCT implementation, preventing HIV/AIDS transmission to the infant, improving attitude and behaviour if both parents are actively involved in PMTCT (AED, 2009). It does make sense, disclosing one's HIV status can be emotionally taxing and comes with fears of rejection, by a partner, whereas if testing together, discovery of each other's status will make life easier and both can receive counselling on coping mechanisms.

AED (2009) prescribes a comprehensive approach to PMTCT and believes that all stakeholders must be actively involved even in PMTCT programme implementation; family, male partners, traditional healers ought to be actively involved in pregnancy and be given proper information on PMTCT to save mothers and children at all levels of the community. AED (2009) further explains the significance of active involvement of these stakeholders to ensure that they do not hold deep-seated traditional beliefs that impede/contradict PMTCT practices such as opposing exclusive feeding methods on cultural grounds if the woman is infected. Botswana has designed a PMTCT peer man programme to compliment the successful and on-going PMTCT peer mother programme. The PMTCT peer man programme seeks to contribute to improved ARV adherence rates among HIV infected pregnant women and their infants, and access to care for those with AIDS defining conditions, increase the number of male partners participating and active in PMTCT programme; increase the number of male peer males trained to provide outreach in target communities, and increase the number of workplaces and homes receiving outreach programmes (AED, 2009).

The impact of male involvement is believed by most researchers to be effective and ensures extended support for a new HIV diagnosed pregnant women, when both parents tested together turn to support each other and work closely to ensure an AIDS free child. Lemens (2010) states that $90 \%$ of estimated 1000 children infected daily with HIV live in SubSaharan Africa and vertical transmission accounts for approximately $95 \%$ of infections in children. Male involvement appears to be meaningfully contributing towards $40 \%$ reduction of vertical transmission and infant mortality.

A study conducted in Mbeya Region in Tanzania concluded that the majority of males support PMTCT interventions. A study included 124 individual interviews and six focus group discussions. The identified barriers to ANC/PMTCT were lack of knowledge/information, no time, neglected importance, the services representing a female responsibility, or fear of HIV test results (Theuring, Mbezi, Luvanda, Harder, Kunz \& Harms, 2009). Only A few males perceived couple HIV counselling/testing as disadvantageous.

Males in Tanzania feel that PMTCT is women orientated and feel that women do not communicate well about their role in PMTCT so did not feel the need to utilise available PMTCT services as a result males have developed evident 
limiting factors against PMTCT, have negative attitudes, and poor knowledge. Tanzanian community continue to stigmatise women infected with HIV/AIDS based on cultural attitudes (Akairo, Deonisia \& Sichoma, 2011).

Several studies have been conducted in Tanzania and clearly obstetric researchers in Tanzania are prolific, and Tanzanian academics are concerned with holistic and comprehensive PMTCT implementation and males are urged to take an active role in PMTCT. In a Tanzanian study, Boniphace (2009) discovered that 103 (74.6\%) from 1238 respondents were not willing to participate in PMTCT programme by accompanying their pregnant partners to ANC and the majority of respondents (61.4\%) have never participated in PMTCT interventions. Males had various reasons for not attending ANC with their partners, their reasons ranged from being busy $(25,2 \%)$, cultural beliefs (21.4\%), lack of knowledge on the importance of partaking in PMTCT (21.4\%).

The best method to involve Zimbabwean men in the prevention of HIV/AIDS was to circumcise them, almost 1.2 million men shall be circumcised in Zimbabwe by 2015 (HST, 2011). Elizabeth Glaser Paediatric AIDS foundation (2011) believes that male involvement in PMTCT can significantly impact women's uptake of HIV-related services and adherence to anti-retroviral drug regimens. Most researchers argue that in traditional context, males have a stronger influence on their female partners' medical care including participation in PMTCT programmes. Males usually dominate the relationship in Sub-Saharan and must be coaxed for full participation in PMTCT and no study in RSA has revealed a strong male participation in PMTCT.

Males are urged to join their pregnant partners in testing for HIV and syphilis in Zambia, a good turnout of males eventually led the Zambian health authorities to complain of the additional strain on health facilities, having limited space and human resources (Elizabeth Glaser Paediatric AIDS foundation, 2011).

A male presence in a female dominated environment shall improve PMTCT programme. Involving males in PMTCT helps to improve gender based violence and HIV risk testing disclosure, and fear of violence strategies for increasing men's involvement. Males are essential in primary prevention of HIV/AIDS among women who are uninfected during pregnancy so that children remain uninfected during and after delivery as most studies revealed that males are more promiscuous than females (Elizabeth Glaser AIDS foundation, 2009).

Males have a special role in PMTCT and must be encouraged to partake significant roles in PMTCT. When a woman discloses her HIV status to a partner they often experience gender based violence and are often blamed for spreading HIV while males actively involved in PMTCT right from the onset of pregnancy have a much better understanding of immunological dynamics and strive to protect the baby and the mother from re-infections. According to Elizabeth Glaser AIDS Foundation (2010), males are pre-judged as having negative attitudes and understating the importance of PMTCT and so make little effort to engage men. Kenya has increased partner involvement in PMTCT, the proportion of male partners who used VCT services as a result of being involved in the programme doubled in one site and increased by $50 \%$ (Elizabeth Glaser AIDS Foundation, 2010).

Male have an important role to play in pregnancy, and PMTCT programme in RSA allows males to be tested with their pregnant partners, be given health education to kerb the spread of HIV/AIDS (DOH, 2010). The researcher while working in ANC for three years did not witness any males accompanying pregnant women, yet the role of the male is always emphasised in ANC health education. Males may also benefit from PMTCT programme through free testing and counselling, and be given a better understanding of reinfection and dangers of unprotected sex with a partner on HAART.

PMTCT at ANC level encourages all pregnant women to book antenatal care, as soon as they believe they are or are confirmed to be pregnant, receive/offered routine ANC including micronutrient supplementation (iron and folate); be offered information on the availability of PMTCT interventions during all health care consultations, be routinely offered HIV counselling and testing and encourage partner or spouse testing, be encouraged to involve partners or spouses in caring for the pregnancy, be counselled on safe sex and provided with condoms, be counselled on safe infant feeding options and assisted in making an appropriate feeding choice, be supported on the choice of infant feeding at all times, be clinically staged and have their CD4 cell count taken, and preferably at the first ANC visit (or at the earliest opportunity), be screened for $\mathrm{TB}$, in line with the BANC (Basic Antenatal care), be screened and treated for syphilis and other sexual transmitted infections; and be given either prophylaxis or HAART depending on the status and clinical indications, commence lifelong ART within two weeks, if tested positive with more than $350 \mathrm{CD} 4$ cell count at 14 weeks of pregnancy or above, initiate prophylaxis regimen being AZT (Zidovudine, NVP (single dose of Nevirapine and Truvada).

The main aim for antiretroviral prophylaxis regimen is to reduce mother-to-child transmission. All other health ethical principles apply that of confidentiality, respect, fair distribution of resources and client autonomy (DOH, 2010). Fast tracking of pregnant HIV infected women is of paramount importance for the South African National Department of Health. According to DOH (2010), women testing positive at any gestational age must be offered following services and clinically staged promptly.

\section{Problem Statement}

Despite several studies conducted on PMTCT and genderinclusiveness, women continue to suffer stereotype comments from their male partners and continue to refuse to do HIV testing, always depend on the pregnant partner HIV status result. There are so underlying factors that hinder 
males from attending ANC and getting tested for HIV, women need support when pregnant and more care is needed when one is diagnosed as HIV positive in pregnancy, hence like was known about Zulu men until the current study was conducted to explore and describe gender-inclusiveness in KwaZulu Natal.

\section{Research Purpose}

The purpose of the study is to explore and describe the range of barriers and motivational factors for gender inclusiveness within the PMTCT programmes in public hospitals in KwaZulu-Natal as perceived by males.

\section{Research Objectives}

Objectives of the study were to:

- Explore the range of barriers and motivation factors for gender inclusiveness within the PMTCT programme as perceived by males.

- Describe the range of barriers and motivation factors for gender inclusiveness within the PMTCT programme as perceived by males.

\section{Research Method and Design}

An explorative, descriptive, qualitative design was used. According to Creswell (2009) qualitative research focuses on an in-depth exploration of a phenomenon and is presented in a narrative form whose aim is to offer meaningful insights. In depth individual interviews were used to capture the depth and breadth of gender inclusiveness within the PMTCT programme as perceived by males in KwaZulu Natal.

\section{Study Setting}

The study was undertaken in KwaZulu Natal Department of Health which has Six Health districts, HIV positive pregnant women are referred to bigger hospitals for comprehensive HIV management in pregnancy. Three bigger hospitals were selected in KZN province for the purpose of the study. Selected hospitals were as follows: one from Ethekwini Health District (about 192 patients attend the clinic daily) which is situated South of the province, one from the central region of the province (about 164 patients attend the clinic daily) which falls under Mgungundlovu Health District and one from from Zululand Health District which is the North of KZN (attending 210 patients daily). The selected hospitals were chosen by geographical representation of the province and the large numbers of patients managed there with HIV in pregnancy. The selected hospitals have big sites for Mother to Child Transmission (MTCT) services and have the largest crisis centre - now called the 'Place of Comfort'.

\section{Population and Target Population}

The population of the study consisted of males whose partners were patients on PMTCT programmes in three selected public hospitals in KwaZulu-Natal. Males whose partners were pregnant and HIV positive patients were the primary target population for the study as the intended service-users of PMTCT programmes.

\section{Sample}

The sample size was determined by the data saturation that was reached after interviewing 13 participants, however the researcher continued with one on one interview to confirm saturation on the $15^{\text {th }}$ participant.

The researcher purposively sampled males whose partners were on PMTCT programme in order to obtain rich data regarding gender inclusiveness in the PMTCT programme.

\section{Data Analysis}

Data was analyzed using the content analysis process outlined by Elo and Kyngas (2008). An inductive development of categories was applied. The main aim was to build a descriptive analysis of the range of barriers and motivation factors for gender inclusiveness within the PMTCT programme and process standards and to build a replicable and valid method for making specific inferences from the text (data collected) to other statements (data interpreted) or properties of its source (Mayring, 2010).

\section{Ethical Considerations}

In ensuring full ethical adherence, the researcher approached the Department of Health in KwaZulu Natal for initial discussion of the research project and to request permission to submit an application to utilize the chosen study sites ahead of obtaining academic ethical clearance from the higher Degrees committee in the Department of Health studies at UNISA. In accordance with this articulated plan, a full proposal of the study was submitted and approved by the Departments Higher Degrees Committee. A formal letter was submitted to the Department of Health requesting site permission for each of the study sites. The letter stated the purpose of the study and the contribution that the study was expected to make towards improving gender inclusiveness in PMTCT programme. Formal permission to access sites was therefore granted. The data collected was coded to ensure that there was no link to participants and only the researcher had access to the raw data and reassurances of commitment to confidentiality was made.

\section{Trustworthiness}

Measures to ensure trustworthiness are described according to Lincoln \& Guba's model (1995). Trustworthiness is a method of establishing or ensuring rigour in qualitative research without sacrificing relevance. Method of trustworthiness involves four criteria namely 
credibility, transferability, dependability and conformability.

Credibility (internal validity): the researcher ensured truthfulness when reporting on male perspectives of gender inclusiveness in PMTCT and motivating factors by spending a long time with the participants; each interview lasted up to 60 minutes. Interviews were conducted in comfortable hospital duty room to ensure comfort and relaxation.

Dependability (reliability): is concerned with results consistency and reproducibility. Researchers gave an explicit description of how research results shall be obtained. The description provided information as to how reproducible the study might be or how unique the situation is.

Confirmability (Objectivity): refers to how neutral the findings are in terms of whether they are reflective of the informants and the enquiry and not a product of the researcher's bias and prejudice. To adhere to the criterion of objectivity, the researcher gave a complete study report to two participants to read through and confirm the truthfulness of the study.

Transferability: refers to showing that the findings have applicability in other contexts. It is attained through purposive non-probability sampling, saturation of data and thick description of the research strategy and method of the study which researchers intend. The findings of the study cannot be applied in other provinces due to cultural diversity in South Africa.

\section{Results and Discussion}

Thematic analysis and content analysis were used to analyse the data and explore and the range of barriers and motivational factors for gender inclusiveness within the (Prevention of mother to child transmission) PMTCT programme in public hospitals in KwaZulu Natal as perceived by males whose partners were patients on the same programme (Creswell, 2009; Elo \& Kyngas, 2008). Views expressed by participants were collated in general thematic groupings to generate "master-theme groupings" and within each of these, more specific sub-themes were identified. Finally, as a way of clarifying how commonly expressed themes were, the appearance of "descriptive terms" was counted and expressed through content analysis. Content analysis has been widely used in nursing studies as a systematic and objective method in quantifying phenomena (Creswell, 2009). The researcher maintained accuracy in data analysis and interpretation by following all the steps of content analysis and categorising emerging findings.

\section{Preparation Phase}

First, three copies were made of the hand written transcripts to facilitate notations within the transcription and the entire text was read. The research data was reviewed on several occasions trying to understand the text; the first reading was just a general overview of the text while the second review focussed on identifying thematic words. Different colour pens were utilised to highlight the main themes and categories. These were then transcribed to a coding sheet. Content analysis facilitated exploring and describing the range of barriers and motivational factors for gender inclusiveness within the PMTCT programme in public hospitals in KwaZulu.

\section{Open Coding and Establishment of Categories}

The second review focussed on underling the thematic words, used to categorise the content into themes and subthemes. Within the text, areas such as perception of roles, motivating barriers in PMTCT programme as perceived by males. Different colour pens were utilised to highlight themes and subthemes which were then transcribed to a coding sheet. Content analysis made it much easier to explore and describe the implementation processes used in the PMTCT programme. Participants' perceptions of PMTCT gender inclusiveness and the manner in which the programme was implemented.

Biographical information.

Table 1.1 Biographical data participants interviewed.

Table 1.1. Biographical data participants interviewed.

\begin{tabular}{lllll}
\hline $\begin{array}{l}\text { Respondent } \\
\text { No. }\end{array}$ & Age & $\begin{array}{l}\text { Marital } \\
\text { status }\end{array}$ & Education level & $\begin{array}{l}\text { Employment } \\
\text { status }\end{array}$ \\
\hline 1 & 20 & Single & primary & Unemployed \\
2 & 23 & Single & secondary & Unemployed \\
3 & 25 & Single & secondary & Unemployed \\
4 & 34 & Married & Primary & Employed \\
5 & 18 & Single & Primary & Unemployed \\
6 & 17 & Single & Still at secondary & Unemployed \\
7 & 18 & Single & Still at secondary & Unemployed \\
8 & 20 & Single & Still at secondary & Unemployed \\
9 & 21 & Single & Still at secondary & Unemployed \\
10 & 25 & Single & Secondary & Unemployed \\
11 & 18 & Single & Still at secondary & Unemployed \\
12 & 17 & Single & Still at secondary & Unemployed \\
13 & 20 & Single & Still at secondary & Unemployed \\
14 & 38 & Single & Matriculant & Employed \\
15 & 37 & Married & Secondary & Employed \\
\hline & & & & \\
\hline
\end{tabular}

Male / Partner Interviews

In the second phase of data collection, the male partners to each of the expectant mothers were interviewed with the primary purpose of understanding what factors they perceived as important influences on whether they were actively involved in the PMTCT sessions involving their partners. To that end, two open-ended questions were presented to the participants and these were,

Please tell me what prevented you from taking part in the mother to child programme?

Please tell me what actions / interventions would motivate you to be part of the mother to child programme?

With regard to understanding the range of perceived barriers, a number of themes were reported as reflected Table 1.2. 
Table 1.2. Themes that emerged from the exploration of factors that acted as barriers to partner involvement.

\begin{tabular}{|c|c|c|}
\hline The & ub-themes emerging from interview feedback & Examplar verbatim statement from participants \\
\hline $\begin{array}{l}\text { Restrictive Policies } \\
\text { within the service- } \\
\text { delivery area. }\end{array}$ & $\begin{array}{l}\text { Lack of service readiness to accommodate partners } \\
\text { in PMTCT services. } \\
\text { Gender inclusivity not planned for in service } \\
\text { planning. }\end{array}$ & $\begin{array}{l}\text { My partner has never been advised to bring me along and never knew that } \\
\text { males are allowed to support pregnant women while attending PMTCT } \\
\text { and that maternal service cater for males as well. } \\
\text { Historically, males have not been allowed in public hospital and this is } \\
\text { new }\end{array}$ \\
\hline $\begin{array}{l}\text { Limited resources to } \\
\text { support the } \\
\text { engagement of } \\
\text { extended family } \\
\text { members beyond the } \\
\text { primary patient. }\end{array}$ & $\begin{array}{l}\text { Service delivery unable to cope with demands from } \\
\text { primary patients. } \\
\text { Inclusion of partners may add unnecessary pressure } \\
\text { to already stretched services. }\end{array}$ & $\begin{array}{l}\text { Nurses always complain about shortage and increased workload, so } \\
\text { bringing us into PMTCT will create even more havoc. } \\
\text { Staff shortage is sometimes an issue, where shall the government extra } \\
\text { nurses from government hospital and clinics have limited resources. I } \\
\text { have seen my wife waiting and waking as early as } 3 \text { am for nothing just to } \\
\text { have excess to ultra sound, now travelling for almost four times for } \\
\text { nothing. }\end{array}$ \\
\hline THEME IDENTIFIED & $\begin{array}{l}\text { HEMES EMERGING FROM INTERVIEW } \\
\text { ACK }\end{array}$ & EXAMPLAR VERBATIM STATEMENT FROM PARTICIPANTS \\
\hline $\begin{array}{l}\text { Gender sensitivity } \\
\text { issues that make } \\
\text { PMTCT services } \\
\text { difficult for males to } \\
\text { be involved with. }\end{array}$ & $\begin{array}{l}\text { Antenatal care services are designed for women. } \\
\text { Male participation may cause discomfort to female } \\
\text { service users. } \\
\text { Male participants view this as a feminine issue. }\end{array}$ & $\begin{array}{l}\text { Women are naked in the clinic, there is no privacy, space is small hardly } \\
\text { enough for pregnant women and no male will appreciate such a congested } \\
\text { environment. } \\
\text { Ever since my wife discovered her positive status she stopped talking to } \\
\text { me and I find it difficult to support a person who is against me. } \\
\text { Even toilets cater only for female patients, they are sanitary towels } \\
\text { everywhere in toilets and as a Zulu man I am not expected to see all that. }\end{array}$ \\
\hline $\begin{array}{l}\text { Cultural beliefs that } \\
\text { support the exclusion } \\
\text { of males }\end{array}$ & $\begin{array}{l}\text { to birth are not for male } \\
\text { sent may lead to bad-luck. } \\
\text { s male involvement. }\end{array}$ & $\begin{array}{l}\text { Pregnancy and newborns are viewed as unclean in my Zulu culture so no } \\
\text { support during pregnancy and immediately after birth. } \\
\text { Seen with many women as a man in Zulu culture implies that one may be } \\
\text { gay. }\end{array}$ \\
\hline THEME IDENTIFIED & $\begin{array}{l}\text { MES EMERGING FROM INTERVIEW } \\
\text { CK }\end{array}$ & EXAMPLAR VERBATIM STATEMENT FROM PARTICIPANTS \\
\hline $\begin{array}{l}\text { Stigma associated with } \\
\text { attendance to PMTCT } \\
\text { services. }\end{array}$ & $\begin{array}{l}\text { PMTCT services associated with HIV/AIDS } \\
\text { stigma. } \\
\text { HIV/AIDS association unwanted and discourages } \\
\text { involvement. } \\
\text { Rejection of mother to be by partner due to stigma } \\
\text { of infection. }\end{array}$ & $\begin{array}{l}\text { Zulu culture allows only females to attend maternal services, so how can } \\
\text { I support something against my culture. } \\
\text { I never had HIV before her; she brought HIV and may as well go alone to } \\
\text { PMTCT to have it treated. }\end{array}$ \\
\hline THEME IDENTIFIED & $\begin{array}{l}\text { SUB-THEMES EMERGING FROM INTERVIEW } \\
\text { FEEDBACK }\end{array}$ & EXAMPLAR VERBATIM STATEMENT FROM PARTICIPANTS \\
\hline $\begin{array}{l}\text { Socio-economic } \\
\text { barriers }\end{array}$ & $\begin{array}{l}\text { Low employment status of partners. } \\
\text { Limited control over work commitments of male } \\
\text { partners. }\end{array}$ & $\begin{array}{l}\text { PMTCT programme is rendered during office hours while I am away at } \\
\text { work so I can never attend it. Although willing. } \\
\text { Honestly, I am drug dealer I have no time to wait in the clinic for } 8 \text { hours } \\
\text { just for one pocket of FDC. }\end{array}$ \\
\hline
\end{tabular}

As noted above, seven major thematic areas were identified as noteworthy influences that acted as barriers for male partners. It is notable that the question relating to the range of possible interventions that could be introduced was asked, the respondents offered very limited responses and often argued that some of the barriers were outside of their powers and that of the service to control. For example, one of the participants indicated that the restrictions associated with his cultural beliefs were between him and his ancestors and that nothing could be done by the clinic to alter this and in fact, there should be an acceptance that for some men, there would be no acceptable basis for their attendance. This was the only categorical rejection from participants. Feedback from other participants identified one noteworthy potential intervention. The participants indicated that they felt that all partners, (regardless of the HIV status of their partner mothers-to-be) should have been required to attend brief PMTCT services.

\section{Limitation of the Study}

The study was done in three selected hospitals thus it is unlikely that the sample represents the whole province of KZN and findings cannot be generalised to other areas in KwaZulu-Natal or South Africa. Secondly, although reassurances of confidentiality and anonymity were addressed in the information and consent sheet it is possible that participants' answers might reflect social desirability bias, given the content of the transcripts this is considered to be a small possibility. The study was qualitative and the results cannot be generalised; there is a need to conduct similar studies in other areas of KZN. 


\section{Recommendations}

1. Service structure: - the design of service provision should be gender sensitive and make accommodations for males to be part of the serviced population. This may require additional monetary investment by health providers.

2. Primary resource capacitation: - the current resources are just adequate to support the women who attend MTCT services and if any expansion in groups to be served occurs, then there will be a pre-requisite need for a total review of resources to ensure that the inclusion of males does not further deprive expectant mothers from the scarce resources they currently have to share amongst themselves.

3. Cultural inclusivity: - there is a need for service development to take full account of issues that could enhance the involvement of males from cultural groups that may have historically opted out of such initiatives. This could include partnering with key cultural leaders to elicit their support for male inclusive PMTCT services.

4. Service accessibility / Flexibility: - General access to services should be widened to cater for those couples who have competing priorities during the usual opening times and where possible, mobile services should be offered to support those with travel difficulties.

5. Gender based sensitivity: - Feedback from potential male service users highlighted a general impression that current service structure was not gender sensitive and any future development of services would require that services be reconfigured and adapted to be inclusive of male requirements.

6. De-stigmatisation Interventions: - PMTCT services have inherent stigma based challenges by virtue of their association with HIV/AIDS and this requires a concerted effort by service developers to work with local communities in educating them about HIV/AIDS to reduce the stigma associated with this area of health care.

\section{Conclusion}

The results of this study highlight key barriers to the inclusion of males in PMTCT services and utilises these findings to propose specific recommendations to promote male inclusion. The engagement of service-users, their partners and professionals simultaneously offers unique insights into this important area of study. Importantly, the study demonstrates that it is possible for researchers to simultaneously consider the attributions for male exclusion from three data without compromising the academic value of the study and in a way that has practical value to serviceusers and service providers alike. By virtue of treading on untested ground with respect to the multi-approach data collection stance adopted, the study has much to learn and will benefit from testing and critique from future researchers.

\section{Acknowledgements}

The researchers wish to thank all the participants for time and assistance, as well as the related stakeholders who ensure the success of the current study.

\section{References}

[1] AED. 2009. Male involvement in PMTCT in Botswana. From: $\mathrm{http} / / /$ coach.fh1360.org/libraries/prevention/male involvemen t_in_PMTCT_Botswana (accessed 10 March 2012).

[2] Akarro, RRJ, Deonisia, M \& Sichona, FJ. 2011. An evaluation of male involvement on the programme for PMTCT of HIV/AIDS: A case study LLala mucipality on Dar es Salaam, Tanzania. Arts and Social Sciences Journal 11(20):1-11.

[3] Boniphace, Y. 2009. Willingness and participation toward prevention of mother to child transmission among males of reproductive age. A study from Kilimanjaro- Tanzania. Tanzania Medical Journal 8(9): 23-26.

[4] CDC. 2011. Domestic Violence Fatality Review. From http://dvfatalityreview.org/2014/09/30/new-from-cdc-2011national-intimate-partner-and-sexual-violence-survey/ (accessed 10 March 2015).

[5] Creswell, JW. 2009. Research Design: qualitative, Quantitative, and Mixed Methods Approaches. Third edition. Lincoln: Sage Publications.

[6] DOH. 2010. Clinical guidelines: PMTCT (Prevention of mother to child transmission). Pretoria: DOH.

[7] DOH. 2010. National Antenatal sentinel HIV and syphilis prevalence survey in South Africa. Pretoria: DOH.

[8] Elo, S. \& Kyngäs, H. 2008, 'The qualitative content analysis process', Journal of Advanced Nursing 62(1), 107-115.

[9] Elizabeth Glaser Paediatric AIDS foundation. 2011. Male involvement in PMTCT: Reaching men through syphilis testing. Study brief. www.pedaids.org/publications/maleinvolvement (accessed 10 March 2012).

[10] Elizabeth Glaser Paediatric AIDS foundation. 2009. Working with men to improve PMTCT outcomes. Presentation transcript. $\quad$ From: www.pedaids.org/publications/maleinvolvement (accessed 10 March 2012).

[11] Health System Trust. 2011. Risk factors for HIV vary between African cities, need tailored responses. From: mhtm/:file:www.hst.org.za (accessed 1 November 2011).

[12] Health System Trust. 2011. Zimbabwe: Rate of male circumcision speeds up. From: $\mathrm{mhtm} /$ :file:www.hst.org.za (accessed 1 November 2011).

[13] KZNHealth, 2012. PMTCT report. From: www.kznhealth.gov.za (accessed 14 February 2012).

[14] Lemens, CL. 2010. Male partner involvement in PMTCT reduces HIV transmission risk. Journal of AIDS. 1(11): 11-16.

[15] Lincoln, YS \& Guba, EG.1985. Naturalistic inquiry. London: Sage. 
[16] Mayring, P. 2010. Qualitative content analysis. Journal of Public Health. 60(54):231:236.

[17] Statistics South Africa. 2011. Mid-year population estimates. From: www.statssa.gov.za (accessed on 17 May 2013).

[18] Theuring, S, Mbezi, P, Luvanda, H, Harder, BJ, Kunz, A \& Harms, G. 2009. Male involvement in PMTCT services in Mbeya Region, Tanzania. Dol Journal 10(1): 1007-1016.

[19] UNAIDS. 2011. Count down to Zero: Global plan towards the elimination of new HIV infections among children by 2015 and keeping their mothers alive 2011-2015. Geneva.

[20] UNFPA, 2011. Annual report 2011. From: www.unfpa.org (accessed 3 March 2013)
[21] WHO. 2010. Technical consultation on elimination of Mother to child transmission of HIV. From: www.int/hiv/events/mtct/en/index/html (accessed 9 September 2011).

[22] WHO. 2010. Key facts on global HIV epidemic and progress in 2010. Progress report 2011. Geneva: WHO

[23] WHO. 2011. Key facts on global HIV epidemic \& progress in 2010. Geneva: WHO publications.

[24] WHO. 2012. MDG5: improve maternal mortality. From: www.who.int/topic/millenium development goals/maternal health (accessed 22 February 2012). 